\title{
THE RESCUE OF RHINOCEROSES AT KARIBA DAM
}

\author{
By A. M. Harthoorn and J. A. Lock
}

The lake damming the Zambezi river at Kariba will eventually be 175 miles long and 2,000 square miles in extent. Much of the flooded land was rich in wild animals. As the country either side of the Zambezi is not a gentle slope, but very hilly, the animals that lived in the inundated areas were not gradually driven away by an advancing tide line, but on the contrary, found the water advancing on them from every side. They were accustomed to floods and merely sought higher ground, but when that in its turn was inundated or remained above the lake only as an island, the marooned animals-if they were not rescued-would either drown or run out of food and starve.

Criticism has been levelled at the principle of this rescue operation and at the financial aspect of wild animals being rescued in one place and shot as a tsetse control measure a few miles away, but rescue operations are not traditionally judged by their profit. Operation Noah is, on the one hand, a splendid example of public opinion facing the repercussions on wild life of its development schemes whilst, on the other hand, fresh evidence is constantly coming to light to refute the value of game destruction as a tsetse control measure.

By 3rd December, 1958, when the dam was closed, the first rescue teams had already been organized. By the end of June, 1959, more than two thousand animals, including mammals of 26 species ranging from buffalo to squirrels, had been saved by rescue teams from Northern and Southern Rhodesia. This figure has since been greatly exceeded.

Some animals, buffalo and elephant for example, swim well and need little assistance; the big cats also tend to escape in time. The antelope, such as bushbuck, impala, sable and kudu remain on their islands, apparently in the hope that the waters will recede. The rescue teams have devised efficient methods of capturing these animals. Mortality has been lowered by the administration of tranquillizers as well as by refinements in driving and netting. But one species, the black rhinoceros, would submit to none of these methods and prolonged attempts to catch one which was stranded on a small island failed. It was not even possible to drive her off the island into the water 


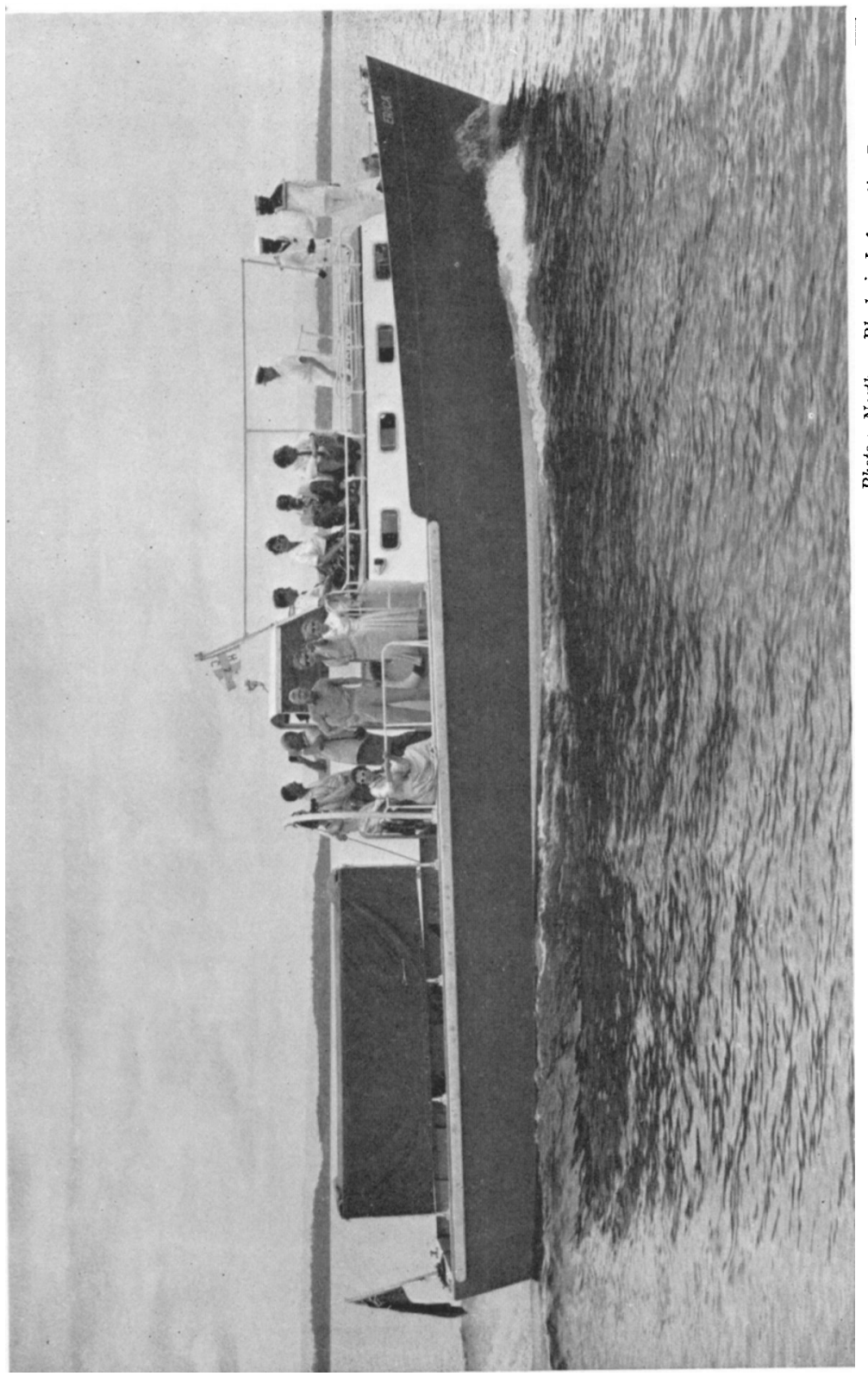

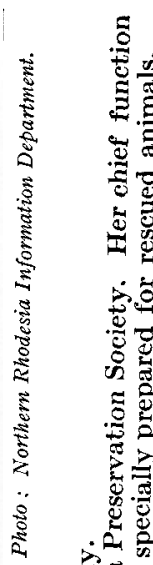

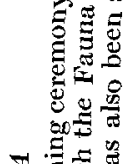

$\nabla \cdot \frac{5}{3}$

无

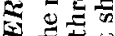

$\therefore$.

30

त

형

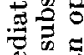

过

苟

政

:

b:

등

z

공

节芯

है

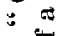

50

놀

두용

马.9 
where her capture would have been easier, even though an aeroplane was eventually used.

When we in Uganda heard that four more rhino were known to be stranded, we offered to apply the drug immobilizing technique which had been proving successful in East Africa, and in May of 1960 set off to Rhodesia. We had already acquired experience in adapting drug immobilizing methods to large animals ; hippopotamus, buffalo and giraffe had been successfully immobilized for transport or marking. Experience with rhino had been obtained during the translocation scheme in Kenya, where these animals are being moved from an area scheduled for bush clearing to other places such as Tsavo National Park. Although the rhino at first presented great problems, especially because of the difficulty of judging their body weight in bush, a proper and safe mixture for immobilizing them had eventually been devised.

The drug was administered with an automatic projectile syringe or dart, carrying a specially designed reinforced needle. The dart was fired from a distance of up to 35 yards into the thick muscle mass of the hindquarters. For the first animal the Palmer Capchur gun was used, powered by carbon-dioxide, and a cross-bow for the remaining three.

\section{The Operation}

A few days before the operation preparations were made to move the rhinoceroses after they had been caught. Mr. Rupert Fothergill, the senior game ranger in charge of the operation, and his rangers constructed with great ingenuity and much hard work, a sledge for moving the animals to the water's edge and a raft floating on eighteen 44-gallon petrol drums. Other work included the cutting of a passage for the raft through the halfsubmerged trees and bush to the mainland. Mr. Fothergill's fine organization of boats and teams of scouts was the principal factor which ensured success.

On Monday morning, the 9th of May, we set out and stalked the first rhino for several hours on an island which measured about half a mile long by a quarter wide, with a neck of land in the middle. Although we approached to within 20 yards of the rhinoceros, it never presented a good enough target to fire the dart; but eventually, at two o'clock in the afternoon, the animal was driven past one of us hidden in a tree and he shot into its neck the dart carrying its dose of muscle relaxant. Within 14 minutes the animal became immobile, enabling the tranquillizer to be administered and the rhinoceros tied up. 
We next rolled the rhinoceros from its side on to its front and then on to the sledge. He was padded in various places, especially beneath the head, with grass-filled sacks. The sledge was drawn to the water's edge by some 30 game scouts, and then on to the raft, where criss-cross ropes prevented any movement that might have upset it.

The 12-mile journey to the mainland took about an hour and a half and it was just before sundown when the sledge was pulled up the lake shore. A light plastic collar was placed on the rhino's neck for quick short-term identification; he was ear-tagged and released. On rising, his first action was to chase his rescuers up trees and into the water.

In June, during another visit to Kariba, three more rhinoceros were similarly rescued. During this operation it was found possible, by using a larger dose of muscle relaxant, to bring about paralysis of the rhinoceros within five to ten minutes. The administration of an antidote then ensured the animal's rapid recovery.

It is desirable that the shortest possible time should elapse between darting an animal and its capture, particularly with large and dangerous species such as rhinoceros. During these operations a suitably designed cross-bow was found to be an efficient and reliable means of firing the dart and its syringe.

One particularly interesting observation made during this rescue showed that the black rhinoceros can swim. The three animals concerned, apparently a family, consisted of a large female estimated at $2,200 \mathrm{lb}$., an adult but slightly smaller male and a young male of approximately 1,000 lb. After the rescue of the female and the youngster, the adult male became very wary and for most of one day could not be found, although the island was no larger than an acre. Towards the end of the day he was seen to be hiding in the water with only the head showing. On the approach of a boat he endeavoured to attack it, and to do so swam more than 25 yards. It was subsequently confirmed that the water was too deep for there to have been any possibility of him wading. Whilst swimming the rhino was very low in the water, his head above the level of his chin, with only the hump on his forequarters above the surface. We formed the impression that he would have drowned had the water been the slightest bit rough.

Observations of a similar nature were made during the landing of the younger male. As soon as he was released on the mainland, where the shore shelved rapidly, this animal charged towards the boat, entering the water and swimming to the back of it. 


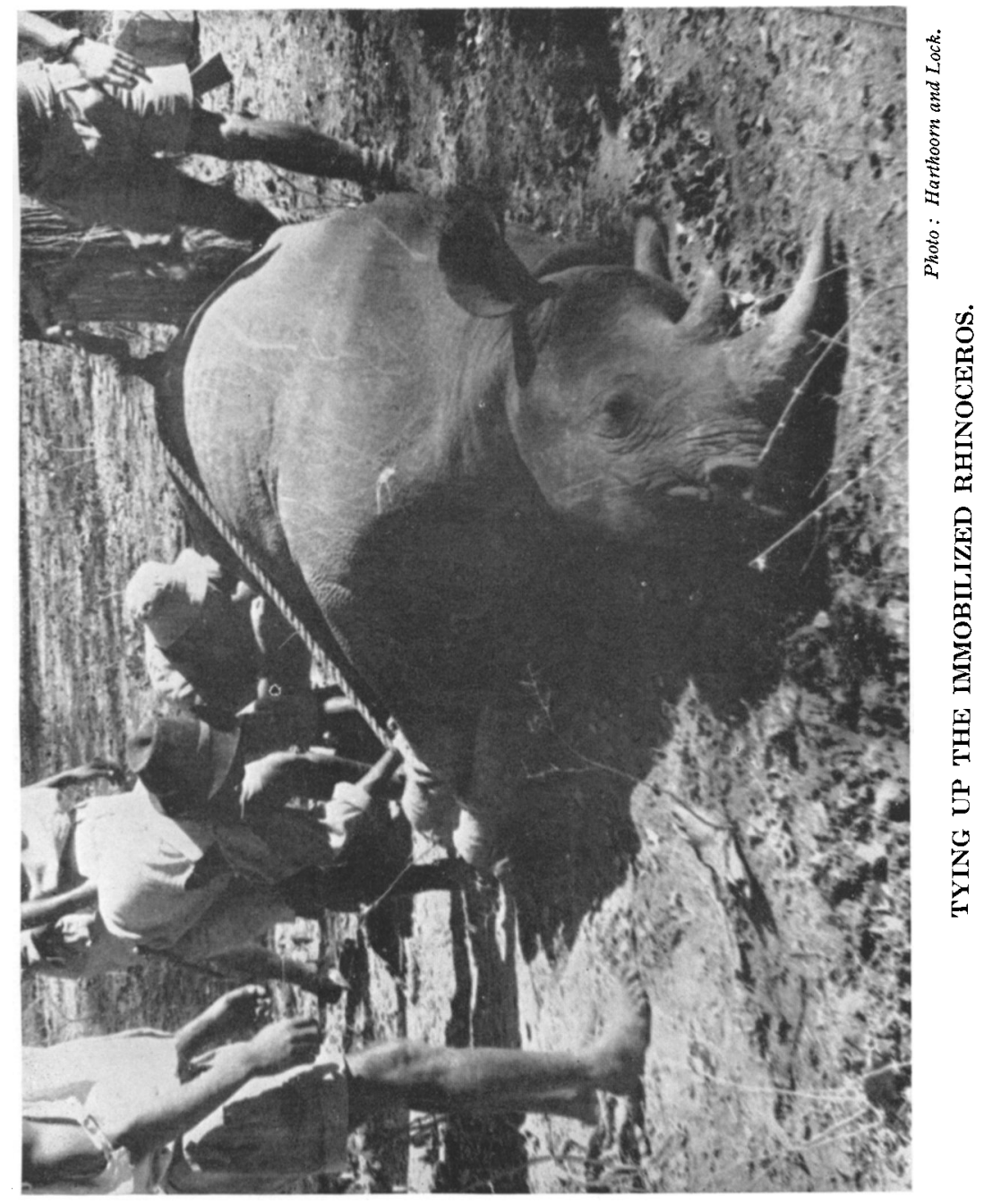




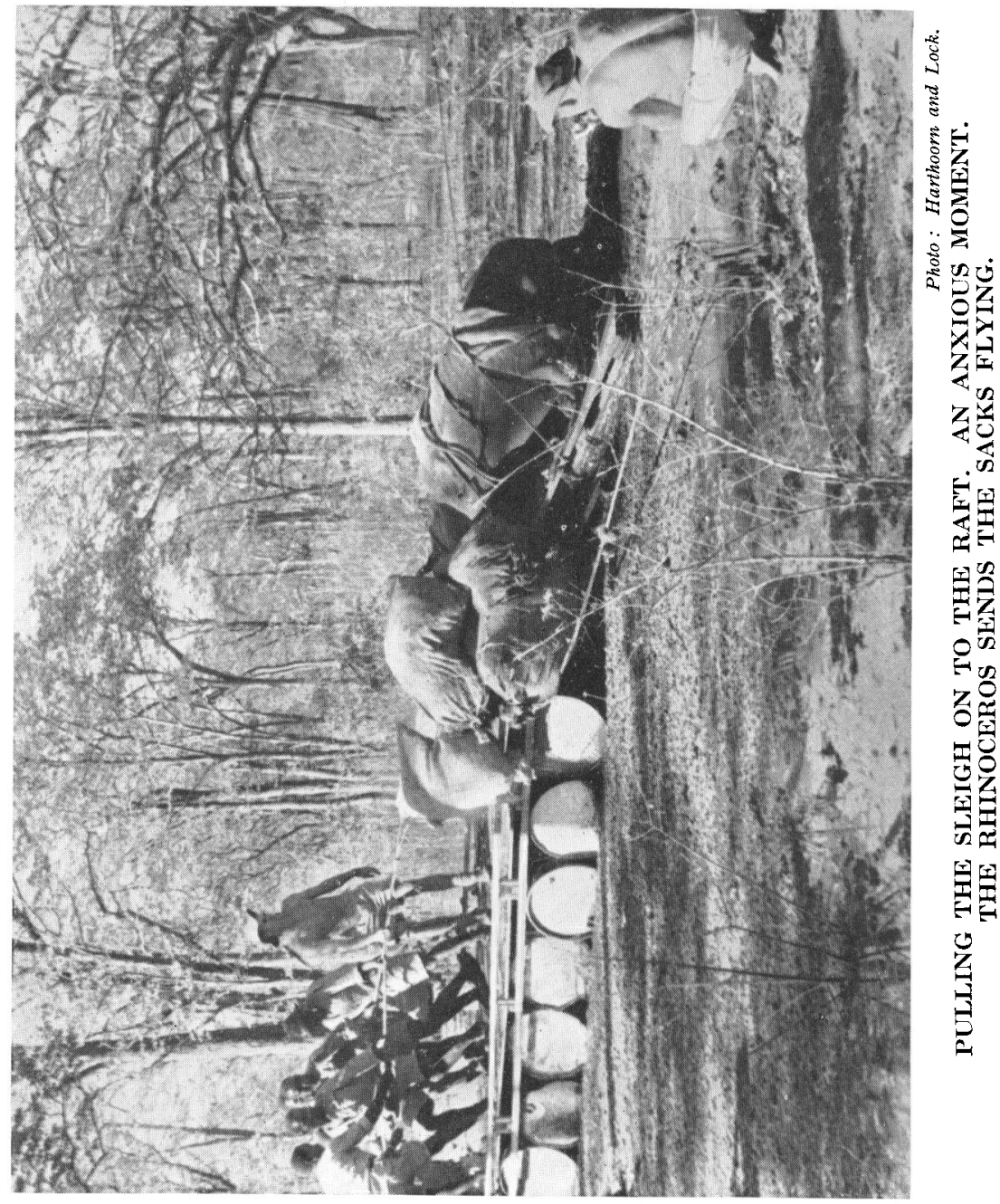




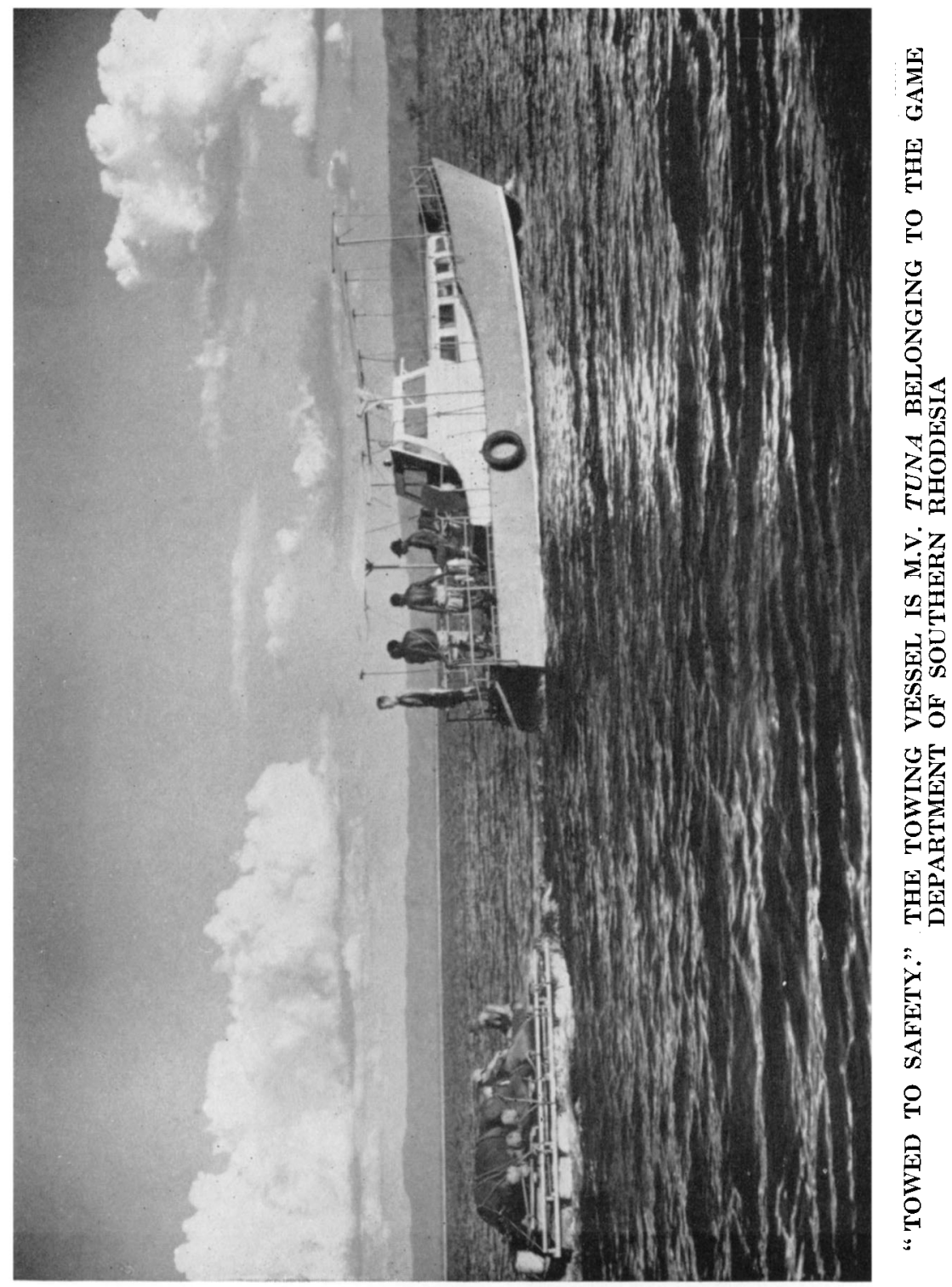




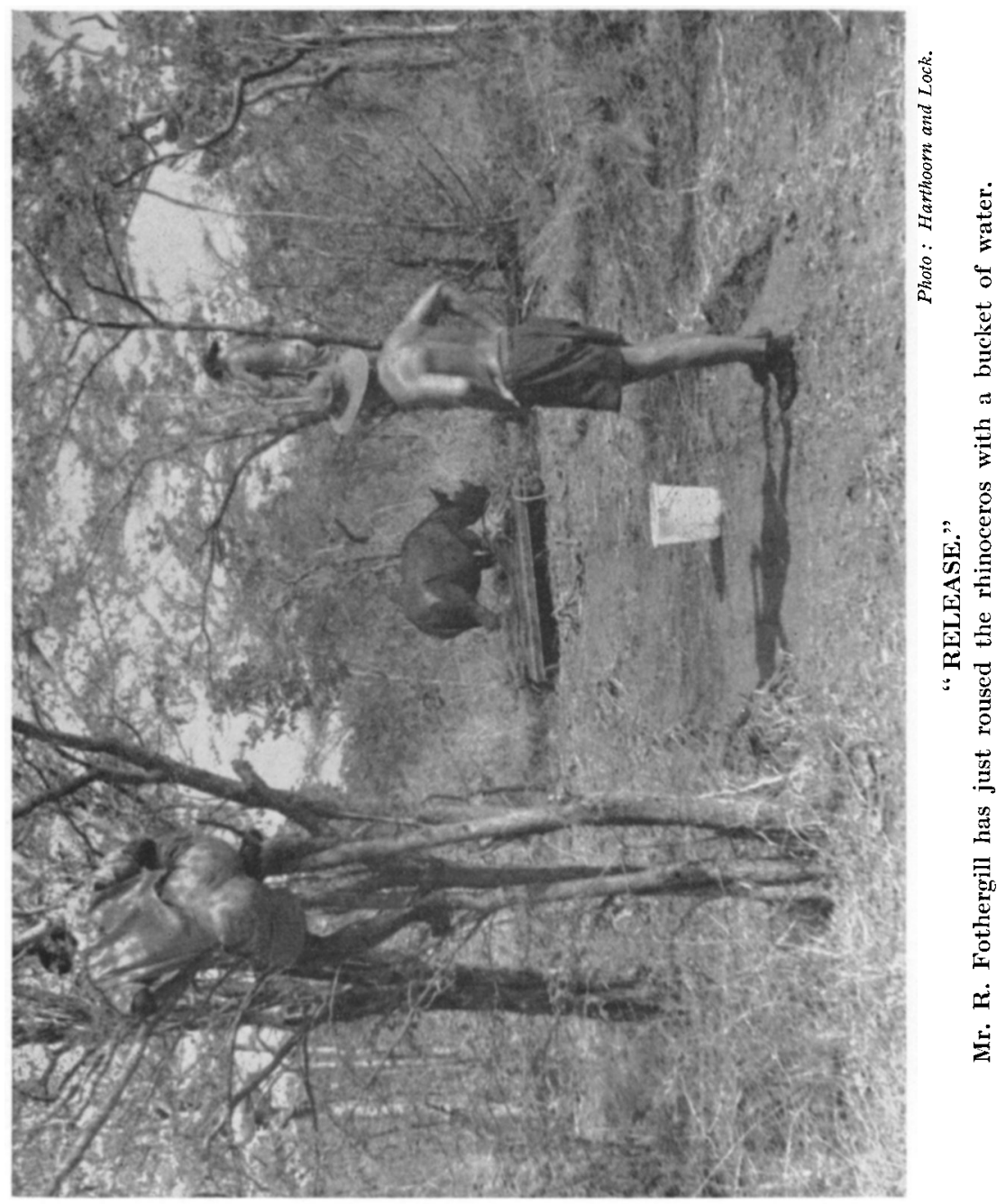


After rather feeble efforts to destroy the outboard motor, he became very distressed, uttered a rather plaintive cry and swam back to the shore where he lay down with his feet still in the water. There he rested for over an hour before going on to dry land. The large dose of tranquillizing drug which he had been given, and the thick water weed, may well have reduced his ability to carry out more prolonged retaliation.

The immobilizing technique, especially when applied to rhinoceros, must be regarded as being still in the experimental stage. Whereas the main drug is a suitable muscle relaxant, various additions to the drug solution which render it safer, are still being tried. Up to date twenty-eight rhinoceros have been darted. We hope eventually to be in a position to give the results of our researches to game departments in Africa and other parts of the world, so that this technique may be used for the preservation and direct management of animals which are difficult to handle by other means.

\section{Acknowledgments}

The initial work on the technique of immobilization of black rhinoceros was assisted by a grant from the Fauna Preservation Society. The journey to Kariba was subscribed by the Southern Rhodesia Department of Game. We are indebted to the Game Department, Southern Rhodesia, and to the Game Preservation and Hunting Association of Northern Rhodesia for assistance and encouragement; to Messrs. May and Baker, Ltd., for donation of Gallamine Triethiodide and Largactil, and to Messrs. Roche Products, Ltd., for the Prostigmine.

\section{REFERENCES}

Buechner, H. K., A. M. Harthoonn and J. A. Lock, 1960. Control of African Wild Animals. Nature, 185, 47.

- 1960. The Immobilizing of African animals in the Field with Special Reference to their Transfer to Other Areas. Proc. Zool. Soc. London, vol. 135, part 2 (in press).

Critchley, R. A., 1959. Operation Noah. Journ. Game Preservation and Hunting Association of Northern Rhodesia.

LANGRIDGE, W. P., 1960. In tsetse control game slaughter is outdated. Journ. Kenya Wild Life Soc., $2,13$.

Owen, R., 1960. Operation Noah. Journ. Game Preservation and IIunting Association of Northern Rhodesia, 2, 123. 